\title{
Quercetin inhibits angiogenesis-mediated human retinoblastoma growth by targeting vascular endothelial growth factor receptor
}

\author{
WEI SONG ${ }^{1}$, XIAOFEI ZHAO ${ }^{1}$, JIARUI XU ${ }^{2}$ and HAN ZHANG ${ }^{1}$ \\ ${ }^{1}$ Department of Ophthalmology, The Second Hospital of Shandong University; \\ ${ }^{2}$ Department of Emergency, Shandong Provincial Hospital, Jinan, Shandong 250000, P.R. China
}

Received March 15, 2016; Accepted February 14, 2017

DOI: $10.3892 / \mathrm{ol} .2017 .6623$

\begin{abstract}
Retinoblastoma (RB) is the most common malignant intraocular cancer in teenagers, occurrence of which depends on the mutation of multiple genes. Among all the signaling pathways involved in the oncogenesis of RB, the process of angiogenesis has been demonstrated to be associated with the local invasive growth and metastasis of this cancer type. Quercetin (Que) is a typical flavonoid and has been reported to inhibit angiogenesis in various types of tumors. In the present study, the effect of Que on RB cells and angiogenesis of RB was evaluated. The human RB Y79 cell line was subjected to treatment with Que of various concentrations. Viability, invasion and migration ability and apoptosis of Y79 cells were subsequently measured to assess the effect of Que on RB cells. In addition, the expression of vascular endothelial growth factor receptor (VEGFR) was also quantified. It was revealed that Que inhibited RB cell growth and invasion in vitro in a dose-dependent manner, with $100 \mu \mathrm{M}$ Que exhibiting the strongest inhibitory effect. In addition, Que downregulated the expression of VEGFR, which was an indicator of the blockade of angiogenesis in RB by targeting VEGF. The effect of Que on angiogenesis was also observed to be dose-dependent. The results of the present study indicated that Que may be a potential anti-RB therapy due to its anti-angiogenesis effect.
\end{abstract}

\section{Introduction}

Retinoblastoma (RB) is the most common childhood malignant ocular tumor, which is characterized by an abnormal appearance of the pupil and leukocoria (1-3). A total of $>9,000$ new cases of RB are reported annually (4), and the incidence may be increased in developing countries; in certain Central and South American countries RB is one of the most common

Correspondence to: Dr Han Zhang, Department of Ophthalmology, The Second Hospital of Shandong University, 247 Beiyuan Road, Jinan, Shandong 250000, P.R. China

E-mail: zhanhan2016@163.com

Key words: quercetin, retinoblastoma, vascular endothelial growth factor, angiogenesis tumor malignancies in youth (5). Generally, onset of RB is initiated by mutation of the $R B 1$ gene, which was the first tumor-suppressor gene to be described (6-8). The majority of patients with RB are born with loss of one $R B 1$ allele and subsequently lose the other one during the development of retinal cells, eventually leading to the carcinogenesis of RB within several years following birth (9).

Currently, treatment modalities for RB include enucleation, systemic chemotherapy, external beam radiation therapy, focal treatments, intra-arterial or subconjunctival chemotherapy (10). However, prognosis of these therapies depends on the stages of RB. To improve the effectiveness of therapy, comprehensive understanding of the mechanism involved in the oncogenesis and development of RB is important. In RB cells, the expression status of numerous genes is substantially altered. These differentially expressed genes include components involved in the immune system, signaling pathways, angiogenesis, cell structure and proliferation (11). Among the potential signaling transductions involved in the genesis of $\mathrm{RB}$, angiogenesis has been demonstrated to be associated with local invasive growth and metastasis of this cancer type (12). In addition, a previous study by Marback et al (13) employed tumor angiogenesis as a prognostic factor for disease dissemination of RB, which confirmed the crucial role of angiogenesis in RB carcinogenesis. Therefore, concatenated application of anti-angiogenic agents and traditional therapies may be synergistic for a greater alleviation of the impairments of RB (14).

Quercetin (Que; 3,30,40,5,7-pentahydroxylflavone) is a typical flavonoid that is widespread in nature and found in fruits, vegetables and plants $(15,16)$. Numerous studies on the effects of Que and associated flavonols on signal transduction associated with carcinogenic processes have been reported, including effects on cell cycle distribution, apoptosis, pro-inflammatory protein induction and angiogenesis (17). Que induced apoptosis in human hepatoma HepG2 cells via activation of the mitochondrial signaling pathway and blockade of Akt and extracellular signal-regulated kinase (18). Duraj et al (19) also demonstrated that Que triggered DNA fragmentation, cleavage of poly-polymerase, modification of B-cell lymphoma (Bcl) and upregulation of Bcl-associated $\mathrm{X}$ protein in human leukemia cells. In addition, the effect of Que on tumor angiogenesis was validated. Que inhibits human prostate tumor growth in an angiogenesis inhibition-dependent manner by targeting vascular endothelial growth factor receptor (VEGFR)-2 (20). 
However, to the best of our knowledge, few studies have focused on the treatment potential of Que against RB. Therefore, it the present study comprehensively investigated the effect of Que on the process of angiogenesis in RB tumors and evaluated its potential as an anti-RB agent.

In the present study, the human RB Y79 cell line was employed as an in vitro model of RB. The cells were subjected to various doses of Que. Cell viability, cell invasion and migration ability, as well as cell apoptosis were subsequently measured to demonstrate the effect of Que on RB cells. To verify the possibility that Que exerted its function in an angiogenesis inhibition-dependent manner, the expression of VEGFR, which is the major mediator of the specific action of VEGF on endothelial cells (20), was subsequently quantified using reverse transcription-quantitative polymerase chain reaction (RT-qPCR), western blotting and immunofluorescence assay. The present study may provide a preliminary illustration of the effect of Que on RB cells and promote the treatment of this malignant cancer.

\section{Materials and methods}

Chemicals and cell culture. Que ( $>99 \%$ pure) was purchased from Sigma-Aldrich (Merck KGaA, Darmstadt, Germany), dissolved in dimethyl sulfoxide (DMSO), aliquoted and stored at $-22^{\circ} \mathrm{C}$. Antibodies against VEGFR (cat. no. ab36844) and GAPDH (cat. no. ab8245) were purchased from Abcam (Cambridge, UK). The human RB Y79 cell line (Shanghai Bioleaf Biotech Co., Ltd., Shanghai, China), preserved at the Second Hospital of Shandong University (Jinan, China), was cultured in HyClone ${ }^{\mathrm{TM}}$ RPMI-1640 medium (GE Healthcare, Logan, UT, USA) supplemented with $10 \%$ fetal bovine serum (Gibco; Thermo Fisher Scientific, Inc., Waltham, MA, USA) and $1 \%(\mathrm{v} / \mathrm{v})$ antibiotics mixture $(100 \mathrm{U} / \mathrm{ml}$ penicillin and $100 \mathrm{U} / \mathrm{ml}$ streptomycin) in an atmosphere of $95 \%$ air and $5 \% \mathrm{CO}_{2}$ at $37^{\circ} \mathrm{C}$.

Administration of Que and VEGF. To assess the effect of Que on RB cells, Y79 cells were divided into four groups: The control group, Y79 cells; the LQUE group, Y79 cells incubated with $25 \mu \mathrm{M}$ Que; the MQUE group, Y79 cells incubated with $50 \mu \mathrm{M}$ Que; and the HQUE group, Y79 cells incubated with $100 \mu \mathrm{M}$ Que.

Cell Counting Kit-8 (CCK-8) assay. The cell viabilities of Y79 cells in different groups were estimated by CCK-8 test. Briefly, $50 \mu \mathrm{l}$ exponentially growing cells $\left(3 \times 10^{3}\right.$ cells $\left./ \mathrm{ml}\right)$ were seeded onto a 96 -well plate and cultured for $72 \mathrm{~h}$ at room temperature. Every $24 \mathrm{~h}$ subsequent to the start of the incubation, $5 \mathrm{mg} / \mathrm{ml}$ of CCK-8 was added to five randomly selected wells in each group. Subsequent to incubation for an additional $4 \mathrm{~h}$ at $37^{\circ} \mathrm{C}$, $200 \mu \mathrm{l}$ of DMSO was added to each well, and the cell viability in the various treatments was assessed by measuring the optical density values at $450 \mathrm{~nm}$ with a microplate reader.

Transwell experiment. The Transwell experiment, which evaluated the migration ability of Y79 cells in various groups, was performed. Incubation medium (with $1 \mathrm{mM} \mathrm{MgCl}_{2} ; 200 \mu \mathrm{l}$ ) containing $1 \times 10^{4}$ cells was seeded into the upper Transwell chambers (Costar; Corning Incorporated, Corning, NY, USA). The cells were subsequently incubated at $37^{\circ} \mathrm{C}$ for $48 \mathrm{~h}$ to allow cell migration through the porous membrane (pore size, $8 \mu \mathrm{m})$. Upon completion of the culture, cells remaining on the upper surface of the chamber were completely removed using a cotton swab. The lower surfaces of the membranes were fixed with $4 \%$ paraformaldehyde for $20 \mathrm{~min}$ and stained in a solution containing $0.5 \%(\mathrm{w} / \mathrm{v})$ crystal violet for 5-10 $\mathrm{min}$ at room temperature. Subsequent to being washed with $\mathrm{ddH}_{2} \mathrm{O}$, results of different groups were observed using the Olympus CX41 microscope (Olympus Corporation, Tokyo, Japan) at x200 magnification and the numbers of cells were determined using Image-Pro Plus 6.0 software (Nikon Corporation, Tokyo, Japan). The invasion ability of Y79 cells was then measured as aforementioned, with polycarbonate membranes pre-coated with $100 \mu \mathrm{l}$ Matrigel (in $0.8 \mu \mathrm{g} / \mu \mathrm{l}$ Dulbecco's modified Eagle's medium; BD Biosciences, San Jose, CA, USA) at $37^{\circ} \mathrm{C}$ for $2 \mathrm{~h}$ to form a reconstituted basement membrane.

Flow cytometry assay. To assess the effect of Que administration on the apoptotic process in Y79 cells in various groups, an Annexin V-fluorescein isothiocyanate (FITC) Apoptosis Detection kit (Jingmei Biotech Co., Ltd., Beijing, China) was employed according to the manufacturer's protocol. The apoptotic rates were analyzed using a FACScan flow cytometer (Accuri ${ }^{\mathrm{TM}}$ C6; BD Biosciences). The apoptotic cell rate was equal to the sum of the late apoptotic rate (upper right quadrant-advanced stage apoptosis cell percentage) and the early apoptotic rate (lower right quadrant-prophase apoptosis cell percentage).

$R T-q P C R$. For RT-qPCR detection, whole RNA in cells from various groups was extracted using TRIzol reagent according to the manufacturer's protocol (Takara Bio, Inc., Otsu, Japan). GAPDH was selected as the reference gene. cDNA templates were achieved by reverse transcribing the RNA using a RT-PCR kit (DBI Bioscience, Shanghai, China), and the final RT-qPCR reaction mixture of volume $20 \mu \mathrm{l}$ contained $10 \mu \mathrm{l}$ of Bestar ${ }^{\circledR}$ SYBR-Green qPCR master mix (DBI Bioscience, Shanghai, China), $0.5 \mu \mathrm{l}$ of each primer (VEGFR forward, 5'-CTCTCT CTGCCTACCTCACCTG-3' and reverse, 5'-CGGCTCTTT CGCTTACTGTTC-3'; and GAPDH forward, 5'-TGTTCG TCATGGGTGTGAA-3' and reverse, 5'-ATGGCATGGACT GTGGTCAT-3'; Sangon Biotech, Shanghai, China), $2 \mu 1$ of the cDNA template and $7 \mu \mathrm{l}$ of RNase-free $\mathrm{H}_{2} \mathrm{O}$. Thermocycling parameters for the amplification were as follows: A denaturation step at $95^{\circ} \mathrm{C}$ for $2 \mathrm{~min}$; followed by 40 cycles at $94^{\circ} \mathrm{C}$ for $20 \mathrm{sec} ; 58^{\circ} \mathrm{C}$ for $20 \mathrm{sec}$, and $72^{\circ} \mathrm{C}$ for $30 \mathrm{sec}$. Relative expression levels of targeted genes were calculated with Data Assist Software version 3.0 (Applied Biosystems; Thermo Fisher Scientific, Inc.) according to the expression of $2^{-\Delta \Delta C q}(21)$.

Western blot analysis. The protein in various samples was extracted for western blot analysis. GAPDH was used as reference protein. Concentrations of protein samples were determined using the bicinchoninic acid method, and $40 \mu \mathrm{g}$ of protein was subject to a $10 \%$ SDS-PAGE. Following transfer of targeted proteins to polyvinylidene difluoride membranes, the membranes were washed with TBS-Tween-20 (TTBS) for 5 min and subsequently incubated with skim milk powder solution for $1 \mathrm{~h}$ at room temperature. Primary antibodies against VEGFR (dilution, 1:1,500) or GAPDH (dilution, 1:1,000) were incubated with membranes at $4^{\circ} \mathrm{C}$ overnight. Following an 


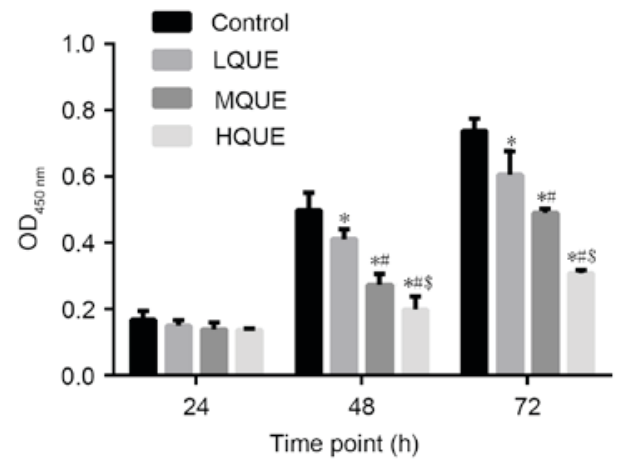

Figure 1. Administration of Que inhibits the proliferation of Y79 cells, and the effect is dose-dependent. " $\mathrm{P}<0.05$, compared with the control group; ${ }^{~} \mathrm{P}<0.05$, compared with the LQUE group; ${ }^{\$} \mathrm{P}<0.05$, compared with the MQUE group. OD, optical density; Que, quercetin; LQUE, Y79 cells incubated with $25 \mu \mathrm{M}$ Que; MQUE, Y79 cells incubated with $50 \mu \mathrm{M}$ Que; HQUE, Y79 cells incubated with $100 \mu \mathrm{M}$ Que.

additional four washes using TTBS, secondary horseradish peroxidase-conjugated IgG antibodies (cat. no. A0216; dilution, 1:20,000; Beyotime Institute of Biotechnology, Haimen, China) were added and incubated with the membranes for $45 \mathrm{~min}$ at $37^{\circ} \mathrm{C}$. Following another six washes using TTBS, the blots were developed using Beyo ECL Plus reagent (Beyotime Institute of Biotechnology) and the results were recorded in the Gel Documentation System (Liuyi, Inc., Beijing, China). The relative expression levels of gremlin 1 and GLI family zinc finger 3 in various samples were calculated with Gel-Pro-Analyzer (Media Cybernetics, Inc., Rockville, MD, USA).

Immunofluorescence assay. The expression of VEGFR in various groups was detected using immunofluorescence microscopy. Briefly, cells $\left(2 \times 10^{6}\right)$ were transferred into a $1.5 \mathrm{ml}$ Eppendorf tube, and supernatant was then discarded following centrifugation for $5 \mathrm{~min}$ at $447 \mathrm{x} \mathrm{g}$ at $37^{\circ} \mathrm{C}$. Subsequent to being washed three times with PBS, cells were centrifuged for $5 \mathrm{~min}$ at $447 \mathrm{x}$ g at $37^{\circ} \mathrm{C}$. Subsequently, cells were transferred to 24-well plates and fixed with $4 \%$ paraformaldehyde for $15 \mathrm{~min}$. The cells were then permeabilized with $0.5 \%$ Triton X-100 for $30 \mathrm{~min}$ at room temperature. Subsequent to being washed with PBS for three cycles, 5 min for each, the cells were blocked in 10\% goat serum (Thermo Fisher Scientific, Inc.) for $15 \mathrm{~min}$. Primary rabbit polyclonal antibodies (dilution, 1:200) to VEGFR were subsequently added and the cells were incubated overnight at $4^{\circ} \mathrm{C}$ in $1 \%$ goat serum. Staining was performed by incubating the cells with FITC-conjugated secondary antibody (cat. no. A0521; Beyotime Biotechnology, Shanghai, China) at dilution of 1:1,000 for $1 \mathrm{~h}$. Following incubation with the secondary antibody, cells were washed and stained with FITC for $5 \mathrm{~min}$ at room temperature. Following three cycles of 5-min washes with PBS buffer, the cells were fixed in slides and imaged with fluorescent microscopy at x400 magnification.

Statistical analysis. All the data were expressed as the mean \pm standard deviation. One-way analysis of variance and post hoc multiple comparisons using a least significant difference method were conducted using SPSS version 19.0 (IBM SPSS, Armonk, NY, USA). P<0.05 was considered to indicate a statistically significant difference.
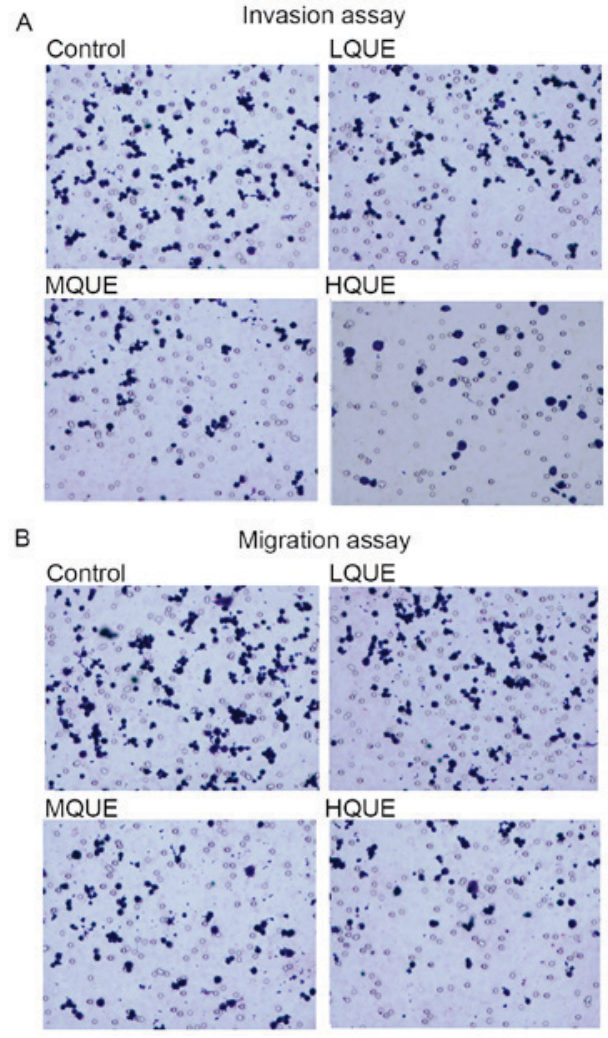

Figure 2. Administration of Que inhibits invasion and migration ability in Y79 cells. The effect was dose-dependent. (A) Detection of invasion ability of Y79 cells in various groups. (B) Detection of migration ability of Y79 cells in various groups. Que, quercetin; LQUE, Y79 cells incubated with $25 \mu \mathrm{M}$ Que; MQUE, Y79 cells incubated with $50 \mu \mathrm{M}$ Que; HQUE, Y79 cells incubated with $100 \mu \mathrm{M}$ Que.

\section{Results}

Administration of Que inhibits proliferation, migration and invasion in Y79 cells. The viability of Y79 cells subsequent to being subjected to Que was examined by CCK-8 assay. A decrease in cell viability due to Que administration was observed for cells sampled from 48 and $72 \mathrm{~h}$ (Fig. 1). The difference between the control group and the MQUE group or the control group and the LQUE group was statistically significant for the last two time points $(\mathrm{P}<0.05)$. In addition, Que affected Y79 cells in a dose-dependent manner, with $100 \mathrm{Mm}$ Que causing the strongest inhibitory effect on the proliferation of Y79 cells. The differences between the LQUE and HQUE groups, the LQUE and MQUE groups, and the MQUE and HQUE groups were all statistically significant for the last two time points $(\mathrm{P}<0.05)$.

Migration and invasion of Y79 cells was detected using Transwell experiments. Exposure to Que markedly reduced the cell numbers moving through the porous membranes (Fig. 2A and B), representing the potential of Y79 to inhibit the metastasis of RB.

Administration of Que induces apoptosis in Y79 cells. The apoptotic process in Y79 cells was also induced by Que administration (Fig. 3). Apoptotic rate of the control group (15.4 $\pm 1.0 \%)$ was significantly different from the other three groups (28.1 $\pm 0.9 \%$ for the LQUE group, $29.3 \pm 0.7 \%$ for the MQUE 


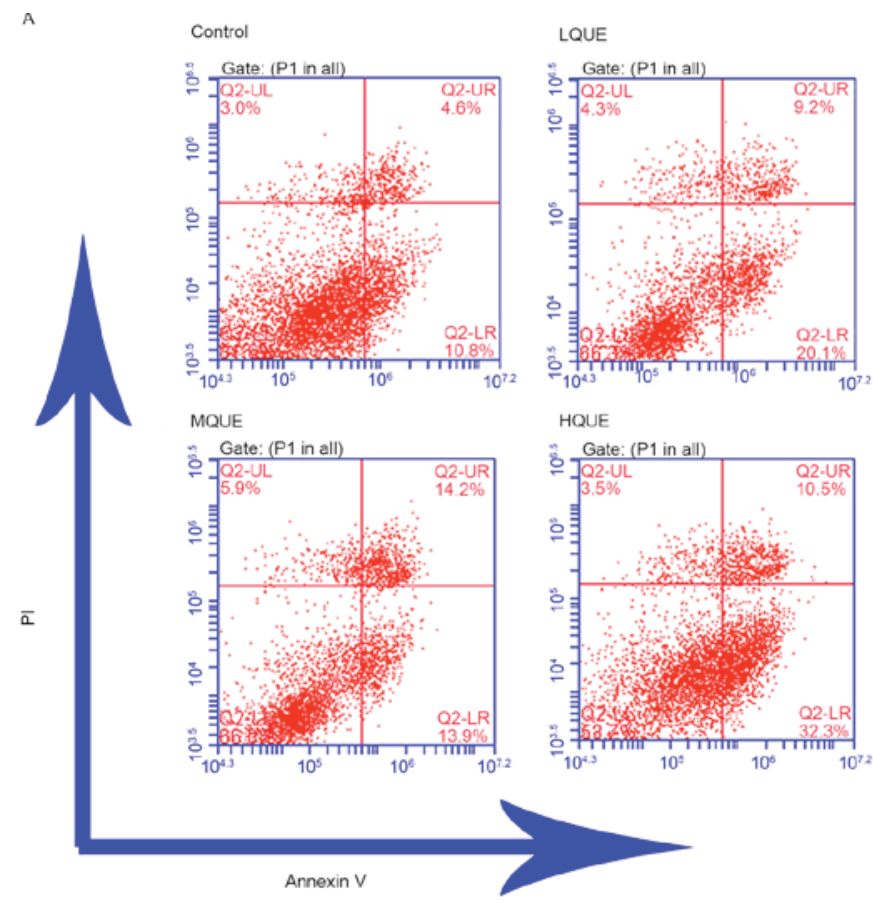

B

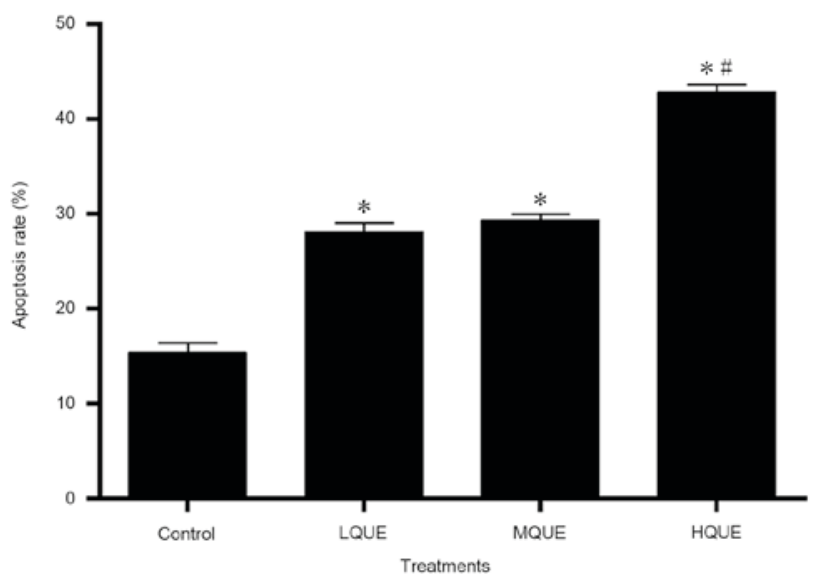

Figure 3. Administration of Que induces apoptosis in Y79 cells, and the effect is dose-dependent. (A) Representative images of flow cytometry results in various groups. (B) Quantitative analysis results of apoptotic rate difference in different groups. ${ }^{*} \mathrm{P}<0.05$, compared with the control group; ${ }^{*} \mathrm{P}<0.05$, compared with the LQUE group. Que, quercetin; LQUE, Y79 cells incubated with $25 \mu \mathrm{M}$ Que; MQUE, Y79 cells incubated with $50 \mu \mathrm{M}$ Que; HQUE, Y79 cells incubated with $100 \mu \mathrm{M}$ Que; PI, propidium iodide.

group and $42.8 \pm 0.8 \%$ for the HQUE group) $(\mathrm{P}<0.05)$. The effect of Que on the apoptosis of Y79 cells was also dose-dependent, but only the data of the HQUE group was significantly increased compared with the other two groups $(\mathrm{P}<0.05)$.

Administration of Que downregulates the level of VEGF at the $m R N A$ and protein levels. Expression of VEGF in Y79 cells post-Que administration was detected using RT-qPCR, western blotting and immunofluorescence assay. At the mRNA level, treatment of Que reduced the transcription of VEGFR, and the differences between the control group and the other three groups were all statistically significant $(\mathrm{P}<0.05$; Fig. $4 \mathrm{~A})$. In addition, the effect of Que on the transcription of VEGFR was also dose-dependent. Similar results were also detected for
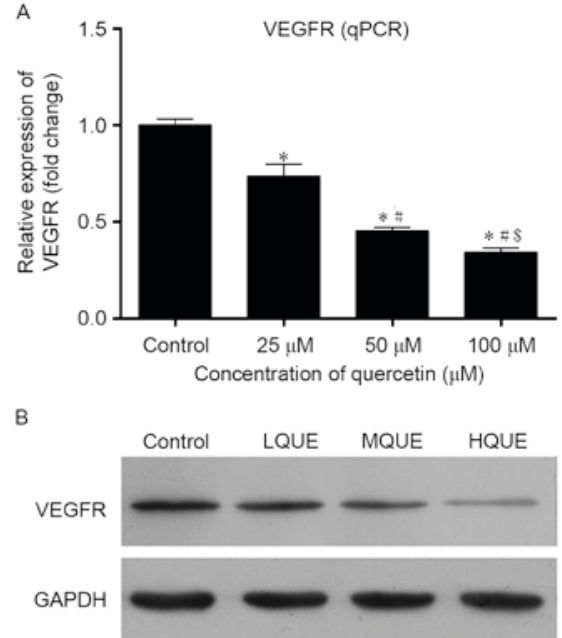

Figure 4. Administration of Que inhibits the expression of VEGFR at the mRNA and protein levels. (A) Quantitative analysis results of relative expression difference of VEGFR in various groups by reverse transcription-qPCR. ${ }^{*} \mathrm{P}<0.05$, compared with the control group; ${ }^{\text {" }} \mathrm{P}<0.05$, compared with the LQUE group; ${ }^{\$} \mathrm{P}<0.05$, compared with the MQUE group. (B) Representative images of western blotting of VEGFR in various groups. Que, quercetin; VEGFR, vascular endothelial growth factor receptor; qPCR, quantitative polymerase chain reaction; LQUE, Y79 cells incubated with $25 \mu \mathrm{M}$ Que; MQUE, Y79 cells incubated with $50 \mu \mathrm{M}$ Que; HQUE, Y79 cells incubated with $100 \mu \mathrm{M}$ Que.

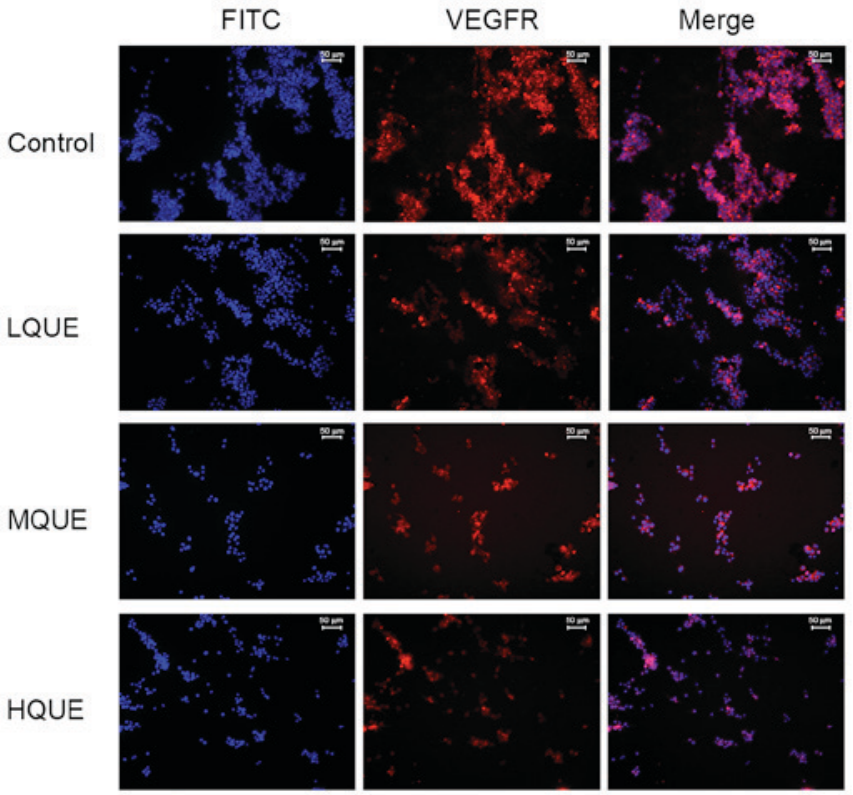

Figure 5. Representative images of immunofluorescence assay of VEGFR in various groups. FITC-positive cells were stained blue. VEGFR-positive cells were stained red. Scale bar, $50 \mu \mathrm{m}$. FITC, fluorescein isothiocyanate; VEGFR, vascular endothelial growth factor receptor; Que, quercetin; LQUE, Y79 cells incubated with $25 \mu \mathrm{M}$ Que; MQUE, Y79 cells incubated with $50 \mu \mathrm{M}$ Que; HQUE, Y79 cells incubated with $100 \mu \mathrm{M}$ Que.

western blot analysis; Que administration inhibited the expression of VEGFR in a dose-dependent manner (Fig. 4B). For detection of the immunofluorescence assay, as shown in Fig. 5, VEGFR-positive cells were stained red and FITC-positive cells were stained blue. It was demonstrated that Que administration decreased the distribution and amount of VEGFR in 
Y79 cells. These results confirmed the antagonizing effect of Que on the process of angiogenesis in RB cells.

\section{Discussion}

Numerous attempts have been made to investigate risk factors in patients with $\mathrm{RB}$, for development of metastatic cases and for extension of RB locally into the orbit (22-24). The majority of these previous studies focused on the degree or extent to which tumor cells invade the optic nerve or choroid in enucleated eyes, and reported a positive association between tumor cell invasion and an increased risk of disseminated disease $(22,23,25,26)$. Currently, the most effective therapy against RB is chemotherapy combined with immunotherapy, which may enhance cytotoxicity on RB by increasing apoptosis (27). Despite its high efficiency, the current treatment scheme remains unsatisfactory considering the general side effects of chemotherapy. Thus, development of mild therapeutic targets to promote treatment of $\mathrm{RB}$ is imperative. In the present study, the effect of Que on RB cells was evaluated. Que has previously been demonstrated to be potent inhibitor against certain prostate, ovarian and colon cancer $(20,28,29)$. Based on the results of the present study, it was revealed that Que is able to inhibit the proliferation, invasion and migration ability, and induces apoptosis in RB cells. In addition, it was demonstrated that Que downregulated angiogenesis in RB cells, which may be the major mechanism through which Que exerted its treatment effect on RB.

It is well known that tumor growth and the formation of hematogenous metastasis depend on angiogenesis, and as a response, tumor cells possessing metastatic potential have accumulated mutations to induce angiogenesis $(30,31)$. Therefore, suppression of angiogenesis may be an important target to inhibit tumor growth and metastasis. Several anti-angiogenic strategies have been developed by targeting various components of tumor angiogenesis $(32,33)$. Of all the potential treatment modalities, numerous phytochemicals have demonstrated potency as antiangiogenic agents during the investigation of cancer development and metastasis (20). In the present study, the cytotoxicity of Que on the human RB Y79 cell line was assessed. The results revealed that Que reduced cell viability and mobility of RB cells, and also induced apoptosis, leading to tumor cell death. These results supported the hypothesis that Que may be a promising agent in the treatment of RB.

Among types of pro-angiogenic mechanisms, the VEGF signaling pathway has been implicated as the central mediator of tumor neovascularization (34). As an attractive therapeutic target, VEGF has been demonstrated to be associated with initiation of angiogenesis by regulating proliferation, migration and differentiation of endothelial cells (35). The function of VEGF is mediated through the activation of receptor tyrosine kinases. In the present study, Que significantly inhibited the level of VEGFR in Y79 cells, which represented the blockade of the VEGF signaling pathway. The present data reported a similar result to a previous study by Pratheeshkumar et al (20) based on prostate cancer, in which the authors reported that Que administration inhibited the activation of VEGFR2, and thereby suppressed the downstream Akt/mechanistic target of rapamycin/P70S6K-mediated angiogenesis signal transduction pathways. A dose-dependent effect of Que on RB cells and VEGFR expression was also observed. However, the suitable concentration of Que for treating RB in the clinic requires additional study.

In conclusion, Que inhibited RB growth and invasion in vitro in a dose-dependent manner. In addition, Que blocked angiogenesis in RB by targeting VEGF. Thus, it may be proposed that Que is a potential anti-RB therapy based on its anti-angiogenic effect. Although the inhibitory effects of Que in vitro were evident, additional studies are required to achieve a comprehensive understanding of the effect and mechanism of this compound on angiogenesis in RB.

\section{Acknowledgements}

The present study was supported by the Youth Foundation of the Second Hospital of Shandong University (grant no. Y2013010064).

\section{References}

1. Menon BS, Alagaratnam J, Juraid EA, Mohamed M, Ibrahim H and Naing NN: Late presentation of retinoblastoma in Malaysia. Pediatr Blood Cancer 52: 215-217, 2009.

2. Bowman RJ, Mafwir MI, Luther P, Luande J and Wood M: Outcome of retinoblastoma in east Africa. Pediatr Blood Cancer 50: 160-162, 2008.

3. Abramson DH, Frank CM, Susman M, Whalen MP, Dunkel IJ and Boyd NW: Presenting signs of retinoblastoma. J Pediatr 132: 505-508, 1998 .

4. Kivelä T: The epidemiological challenge of the most frequent eye cancer: Retinoblastoma, an issue of birth and death. Brit J Ophthalmol 93: 1129-1131, 2009.

5. Leal-Leal C, Flores-Rojo M, Medina-Sansón A, Cerecedo-Díaz F, Sánchez-Félix S, González-Ramella O, Pérez-Pérez F, Gómez-Martínez R, Quero-Hernández A, Altamirano-Alvarez $\mathrm{E}$, et al: A multicentre report from the Mexican Retinoblastoma Group. Br J Ophthalmol 88: 1074-1077, 2004.

6. Comings DE: A general theory of carcinogenesis. Proc Natl Acad Sci USA 70: 3324-3328, 1973.

7. Friend SH, Bernards RA, Rogelj S, Weinberg RA, Rapaport JM, Albert DM and Dryja TP: A human DNA segment with properties of the gene that predisposes to retinoblastoma and osteosarcoma. Nature 323: 643-646, 1986.

8. Alfred G and Knudson AG Jr: Mutation and cancer: Statistical study of retinoblastoma. Proc Natl Acad Sci USA 68: 820-823, 1971.

9. Dimaras H, Kimani K, Dimba EA, Gronsdahl P, White A, Chan HS and Gallie BL: Retinoblastoma. Lancet 379: 1436-1446, 2012.

10. Shields CL and Shields JA: Basic understanding of current classification and management of retinoblastoma. Curr Opin Ophthalmol 17: 228-234, 2006.

11. Saxena P and Kaur J: Differential expression of genes in retinoblastoma. Clin Chim Acta 412: 2015-2021, 2011.

12. Rossler J, Dietrich T, Pavlakovic H, Schweigerer L, Havers W, Schüler A, Bornfeld N and Schilling H: Higher vessel densities in retinoblastoma with local invasive growth and metastasis. Am J Pathol 164: 391-394, 2004.

13. Marback EF, Arias VEA, Paranhos A Jr, Soares FA, Murphree AL and Erwenne CM: Tumour angiogenesis as a prognostic factor for disease dissemination in retinoblastoma. Br J Ophthalmol 87: 1224-1228, 2003.

14. Houston SK, Murray TG, Wolfe SQ and Fernandes CE: Current update on retinoblastoma. Int Ophthalmol Clin 51: 77-91, 2011.

15. Slusarz A, Shenouda NS, Sakla MS, Drenkhahn SK, Narula AS, MacDonald RS, Besch-Williford CL and Lubahn DB: Common botanical compounds inhibit the hedgehog signaling pathway in prostate cancer. Cancer Res 70: 3382-3390, 2010.

16. Comalada M, Camuesco D, Sierra S, Ballester I, Xaus J, Gálvez J and Zarzuelo A: In vivo quercitrin anti-inflammatory effect involves release of quercetin, which inhibits inflammation through down-regulation of the NF-kappaB pathway. Eur J Immunol 35: 584-592, 2005. 
17. Murakami A, Ashida $\mathrm{H}$ and Terao J: Multitargeted cancer prevention by quercetin. Cancer Lett 269: 315-325, 2008.

18. Granado-Serrano AB, Martin MA, Bravo L, Goya L and Ramos S: Quercetin induces apoptosis via caspase activation, regulation of Bcl-2 and inhibition of PI-3-kinase/Akt and ERK pathways in a human hepatoma cell line (HepG2). J Nutr 136: 2715-2721, 2006.

19. Duraj J, Zazrivcova K, Bodo J, Sulikova M and Sedlak J: Flavonoid quercetin, but not apigenin or luteolin, induced apoptosis in human myeloid leukemia cells and their resistant variants. Neoplasma 52: 273-279, 2004

20. Pratheeshkumar P, Budhraja A, Son YO, Wang X, Zhang Z, Ding S, Wang L, Hitron A, Lee JC, Xu M, et al: Quercetin inhibits angiogenesis mediated human prostate tumor growth by targeting VEGFR-2 regulated AKT/mTOR/P70S6K signaling pathways. PLoS One 7: e47516, 2012.

21. Livak KJ and Schmittgen TD: Analysis of relative gene expression data using real-time quantitative PCR and the 2(-Dela Delta C(T)) method. Methods 25: 402-408, 2001.

22. Merriam GR Jr: Retinoblastoma; analysis of 17 autopsies. Arch Ophthal 44: 71-108, 1950.

23. Carbajal UM: Metastasis in retinoblastoma. Am J Ophthalmol 48 47-69, 1959

24. Taktikos A: Investigation of retinoblastoma with special reference to histology and prognosis. Br J Ophthalmol 50: 225-234, 1966.

25. Rubin CM, Robison LL, Cameron JD, Woods WG, Nesbit ME Jr, Krivit W, Kim TH, Letson RD and Ramsay NK: Intraocular retinoblastoma group V: An analysis of prognostic factors. J Clin Oncol 3: 680-685, 1985 .

26. Kopelman JE, McLean IW and Rosenberg SH: Multivariate analysis of risk factors for metastasis in retinoblastoma treated by enucleation. Ophthalmology 94: 371-377, 1987.
27. Liu Q, Wang Y, Wang H, Liu Y, Liu T and Kunda PE: Tandem therapy for retinoblastoma: Immunotherapy and chemotherapy enhance cytotoxicity on retinoblastoma by increasing apoptosis. J Cancer Res Clin Oncol 139: 1357-1372, 2013.

28. Ren MX, Deng XH, Ai F, Yuan GY and Song HY: Effect of quercetin on the proliferation of the human ovarian cancer cell line SKOV-3 in vitro. Exp Ther Med 10: 579-583, 2015.

29. Park CH, Chang JY, Hahm ER, Park S, Kim HK and Yang $\mathrm{CH}$ Quercetin, a potent inhibitor against beta-catenin/Tcf signaling in SW480 colon cancer cells. Biochem Biophys Res Commun 328: 227-234, 2005.

30. Folkman J, Watson K, Ingber D and Hanahan D: Induction of angiogenesis during the transition from hyperplasia to neoplasia. Nature 339: 58-61, 1989.

31. Liotta LA, Steeg PS and Stetler-Stevenson WG: Cancer metastasis and angiogenesis: An imbalance of positive and negative regulation. Cell 64: 327-336, 1991

32. Tang N, Shi L, Yu Z, Dong P, Wang C, Huo X, Zhang B, Huang S, Deng S, Liu K, et al: Gamabufotalin, a major derivative of bufadienolide, inhibits VEGF-induced angiogenesis by suppressing VEGFR-2 signaling pathway. Oncotarget 7: 3533-3547, 2016.

33. Zhang Z, Zhang H, Peng T, Li D and Xu J: Melittin suppresses cathepsin $\mathrm{S}$-induced invasion and angiogenesis via blocking of the VEGF-A/VEGFR-2/MEK1/ERK1/2 pathway in human hepatocellular carcinoma. Oncol Lett 11: 610-618, 2016.

34. Keck PJ, Hauser SD, Krivi G, Sanzo K, Warren T, Feder J and Connolly DT: Vascular permeability factor, an endothelial cell mitogen related to PDGF. Science 246: 1309-1312, 1989.

35. Tie J and Desai J: Antiangiogenic therapies targeting the vascular endothelia growth factor signaling system. Crit Rev Oncog 17: 51-67, 2012. 